\title{
A Dilemma in the Extremely Low-Placed Venus A-Valve in a Cardiogenic Shock Patient
}

\author{
Mi Chen, MD,${ }^{1,2}$ Honglei Zhao, MD, PhD,${ }^{1}$ Yan Ding, MD, ${ }^{1}$ Lizhong Sun, $\mathrm{MD}, \mathrm{PhD}^{1}$ \\ ${ }^{1}$ Department of Cardiac Surgery, Beijing Anzhen Hospital, Capital Medical University, Beijing, China; \\ ${ }^{2}$ Department of Cardiac Surgery, University Hospital of Zurich, Zurich, Switzerland
}

\section{ABSTRACT}

Transcatheter aortic valve replacement (TAVR) is regarded as an alternative to balloon aortic valvuloplasty in patients with severe aortic valve stenosis in cardiogenic shock. A low implantation of transcatheter heart valve (THV) can result in "supraskirt" paravalvular aortic regurgitation (PAR) and prosthesis-patient mismatch (P-PM), causing a dilemma in such a setting. A 64-year-old man presented to our emergency department with severe aortic stenosis and acute heart failure causing cardiogenic shock. An urgent transfemoral TAVR was performed under general anesthesia in a hybrid room. Predilatation was performed with a 22-mm compliant balloon, and a 26-mm Venus A-Valve (Venus MedTech, Hangzhou, China) was deployed. After valve implantation, the hemodynamic conditions of the patient rapidly deteriorated; therefore, cardiopulmonary resuscitation and extracorporeal circulation support were initiated. Aortography and transthoracic echocardiography (TEE) illustrated an extremely low implantation of THV, with moderate to severe supraskirt PAR and moderate P-PM. After evaluation of the hemodynamic tolerability of PAR, a median sternotomy was done, and surgery was performed. The patient died due to severe sepsis and hyperkalemia 14 days after the procedure. The management of urgent TAVR in cardiogenic shock should be revised and reexamined. A widespread and practical percutaneous technique to manage implant failure of THV is required to avoid surgical bailout.

\section{INTRODUCTION}

Transcatheter aortic valve replacement (TAVR) is regarded as an alternative in patients with severe aortic valve stenosis in cardiogenic shock [Fraccaro 2020]. The main technical limitation of the many first-generation self-expandable devices, including the Venus A-Valve device (Venus MedTech, Hangzhou, China), is the inability to recapture and reposition.

Received December 7, 2020; received in revised form fanuary 12, 2021; accepted fanuary 12, 2021.

Correspondence: Lizhong Sun, MD, PbD, Department of Cardiac Surgery, Beijing Anzhen Hospital, Capital Medical University, 2 Anzhen Rd, Beijing 10029, China; (010) 64456613 (e-mail: lizhongsun@foxmail.com).
Implant failure of THV in cardiogenic shock patients can be life-threatening, given that it increases the intractability of the patient's hemodynamics. A case of emergent TAVR resulting in an extremely low-placed Venus A-Valve is presented here with approval from our institutional review board and informed consent.

\section{CASE REPORT}

A 64-year-old man with a history of hypertension, gastrointestinal bleeding, and chronic kidney disease presented to our emergency department complaining of orthopnea and fatigue with progressive aggravation in the last month. He had acute upper gastrointestinal bleeding 1 month earlier and underwent medical treatment. On physical examination, we documented a midsystolic murmur along the upper right sternal border and pansystolic murmur over the apex. He was in heart failure, with coarse crackling and wheezing in both lungs. He had New York Heart Association class IV symptoms with EuroSCORE II of $20 \%$. He was lean: height $175 \mathrm{~cm}$ and weight $53 \mathrm{~kg}$.

Transthoracic echocardiography (TEE) demonstrated severe aortic stenosis and severe mitral regurgitation (MR) with left ventricular ejection fraction of $46 \%$ (left ventricular end-diastolic diameter, $58 \mathrm{~mm}$; left ventricular end-systolic diameter, $45 \mathrm{~mm}$; aortic valve mean pressure gradient, 50 $\mathrm{mmHg}$; aortic valve $\mathrm{V}_{\max }, 455 \mathrm{~cm} / \mathrm{s}$; mitral valve regurgitation, $3+)$. The mitral valve showed poor coaptation of the leaflets. Contrast-enhanced computed tomography-derived annular area perimeter measurements were $428.9 \mathrm{~mm}^{2}$ and $74.8 \mathrm{~mm}$, respectively, mandating a $22-\mathrm{mm}$ Venus balloon to predilate and a 26-mm Venus A-Valve to implant.

The patient's symptoms and frailty, the burden of comorbidities, and technical aspects were evaluated by a multidisciplinary heart team. The heart team decided to proceed with urgent TAVR with a Venus A-Valve and reassess mitral regurgitation after TAVR. Preoperative management included inotropic therapy, morphine injection, and blood transfusion. The procedure was performed by a multidisciplinary team including cardiologists, cardiac surgeons, perfusionist, echocardiographer, and anesthesiologists in a hybrid operating room with wet-primed cardiopulmonary bypass circuits on standby. General anesthesia was induced using midazolam $2 \mathrm{mg}$, sufentanil $20 \mu \mathrm{g}$, and etomidate $10 \mathrm{mg}$. Continuous infusion of norepinephrine $(0.03 \mu \mathrm{g} / \mathrm{kg} / \mathrm{min})$ and intravenous fluid therapy $(15 \mathrm{ml} / \mathrm{kg} / \mathrm{min})$ were commenced to restore 
hemodynamic stability, with systolic blood pressure in the range of 90 to $120 \mathrm{mmHg}$.

After exposure of the right femoral artery, systolic blood pressure dropped to $60 \mathrm{mmHg}$ gradually. Added doses of 0.1 , 0.3 , and $0.6 \mathrm{mg}$ intravenous adrenaline failed to raise systolic blood pressure above $40 \mathrm{mmHg}$. At this point, heparin was administered intravenously to achieve an activated clotting time $>250 \mathrm{~s}$. After crossing of the stenotic valve, an extrastiff guidewire (Lunderquist Cook Medical, Bloomington, IN) was positioned into the left ventricle, and an emergent balloon aortic valvuloplasty was performed with a $22-\mathrm{mm}$ Z-MED balloon (Braun Interventional Systems, Bethlehem, PA). Instead of the expected hemodynamic recovery after predilatation, the patient developed shock and arrested despite the cumulative doses of vasopressors used. Cardiopulmonary resuscitation was started, and systolic blood pressure remained $<80 \mathrm{mmHg}$.

A 19-Fr-equivalent, 26-mm self-expanding Venus A-Valve was implanted via the right femoral artery. Extracorporeal circulation was established via femoral cannulation, and adequate perfusion pressure was achieved. Aortography and TEE showed an extremely low implantation (Figure 1) and moderate to severe "supraskirt" PAR (Figures 2 and 3) [Pibarot 2015]. TEE in short-axis view showed a moderate to severe PAR originating from the left and right coronary cusps and moderate prosthetic aortic valve stenosis (aortic valve mean pressure gradient, $29 \mathrm{mmHg}$; aortic valve $\mathrm{V}_{\text {max }_{2}} 339 \mathrm{~cm} / \mathrm{s}$ ).

After evaluating the hemodynamic tolerability of PAR, moderate P-PM [Jilaihawi 2010], the initial severe mitral regurgitation, and potential impaired mobility of the anterior leaflet of the mitral valve due to the low deployment, the heart team decided to proceed with aortic valve replacement and mitral valve replacement rather than valve-in-valve TAVR [Ussia 2011]. A median sternotomy was done, and the Venus A-Valve was removed after infiltration with ice water (Figure 4). A $25-\mathrm{mm}$ St. Jude Medical mechanical mitral prosthesis and a 19-mm St. Jude Medical Regent aortic prosthesis were implanted (St Jude Medical, St Paul, MN). The cross-clamping time was $105 \mathrm{~min}$, and the cardiopulmonary bypass time was $245 \mathrm{~min}$.

The patient was awake on day 1 after the procedure, and tracheal intubation was removed on day 2 . The patient underwent continuous renal replacement therapy and early antimicrobial therapy. A tracheotomy was performed on day 11 because of acute respiratory distress syndrome. The patient went into cardiopulmonary arrest and died on day 14 from severe sepsis and hyperkalemia.

\section{DISCUSSION}

Severe aortic valve stenosis and cardiogenic shock have a poor prognosis, with high morbidity and mortality. According to guidelines, balloon aortic valvotomy may be considered as a bridge to surgery or TAVR in hemodynamically unstable patients [Baumgartner 2017]. Fraccaro et al [2020] reported that TAVR may be a safer and more feasible option in cardiogenic shock in midterm outcomes than balloon aortic

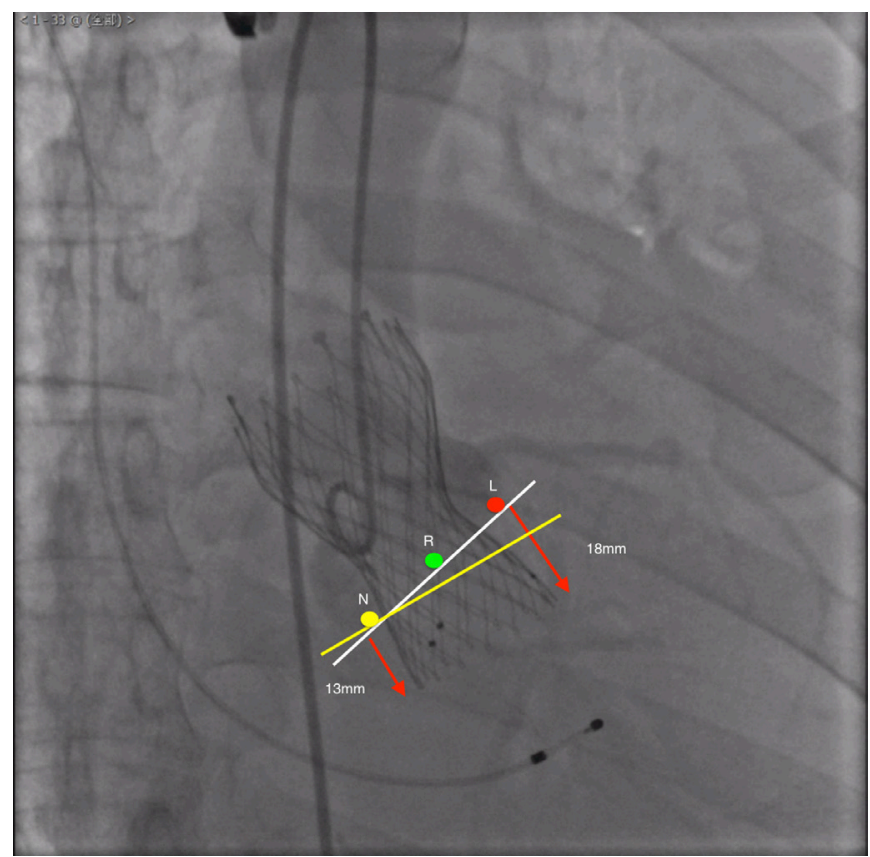

Figure 1. Aortography demonstrated that the distal part of the frame was $13 \mathrm{~mm}$ below the nadir of the noncoronary cusp (NCC) and 18 $\mathrm{mm}$ below the nadir of the left coronary cusp (LCC), whereas the new bioprosthetic aortic annulus was in the height of $15 \mathrm{~mm}$ of the frame (yellow line). The white line indicates the aortic annulus level. $L$ indicates left coronary cusp; $\mathrm{N}$, noncoronary cusp; R, right coronary cusp.

valvotomy. Our case presents a trial-and-error procedure as follows: (1) no hemodynamic improvement after balloon aortic valvotomy; (2) TAVR but implant failure; and (3) surgical aortic and mitral valve replacement with grim prognosis. With limited operator experience in TAVR and use of the Venus A-Valve device, the outcomes of emergent TAVR are supposed to be improved. TAVR is still regarded as an appropriate treatment for inoperable patients with severe aortic valve stenosis and cardiogenic shock, which was also illustrated by Fraccaro et al [2020], with $94 \%$ device success for emergent TAVR by transfemoral access. Even though evidence is lacking to standardize the emergent TAVR procedure, refinement of TAVR devices and increasing operator experience may reduce TAVR procedural complications.

Unlike more common complications such as vascular complications, cerebrovascular events, and coronary obstruction, THV malposition has been described rarely. THV malposition can be classified as THV embolization, THV misplacement, and suboptimal deployment based on the severity of migration (Table 1). THV embolization is defined as severe migration of the THV, resulting in complete detachment from the aortic annulus and migration into either the ascending aorta or the left ventricle outflow tract (LVOT) [Ibebuogu 2015; Sarkar 2012; Tay 2011; Makkar 2013; Geisbusch 2010]. THV misplacement is defined as moderate migration of the THV. The THV remains fixed to the aortic annulus, but the misplacement of the THV leads to related complications such as supraskirt PAR, P-PM, 


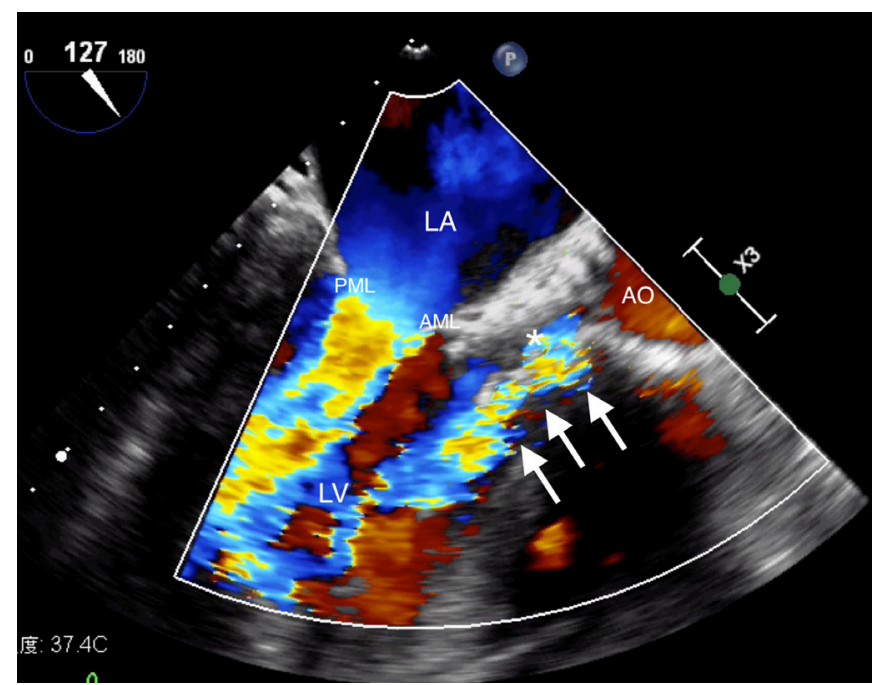

Figure 2. The long-axis view of TEE shows moderate to severe paravalvular regurgitation (white arrows; prosthesis marked with an asterisk) and potential influence on the movement of the mitral anterior leaflet owing to the low-placed flame. AML indicates anterior mitral leaflet; $A O$, aorta; LA, left atrium; LV, left ventricle; PML, posterior mitral leaflet.

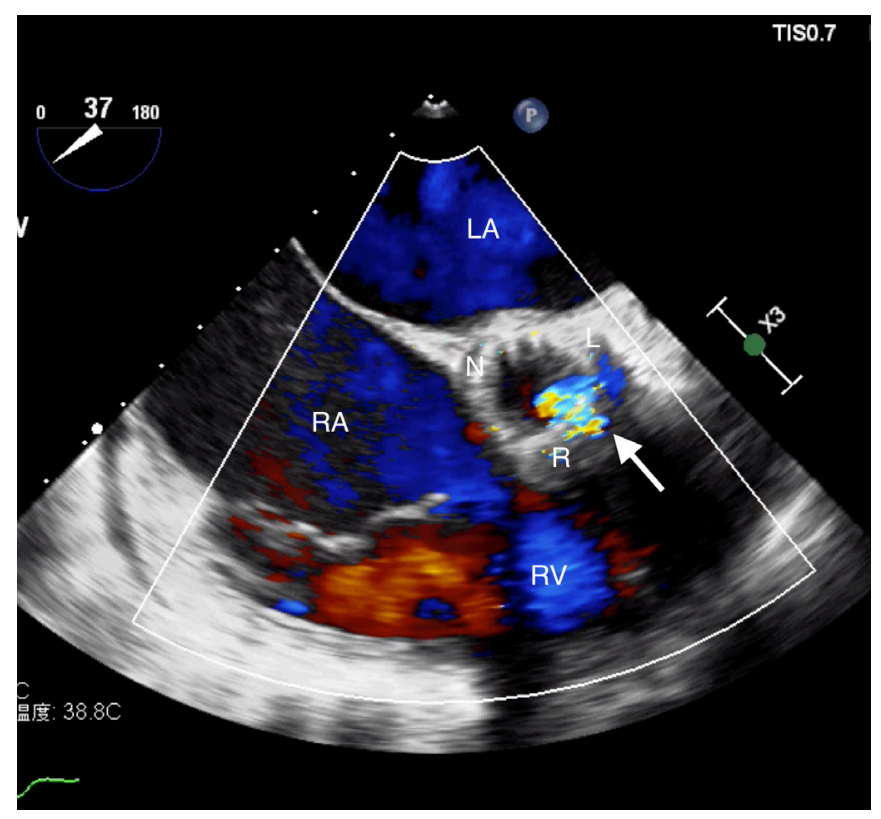

Figure 3. The short-axis view of TEE shows supraskirt aortic regurgitation originating from the left and right coronary cusps (white arrow). L indicates left coronary cusp; LA, left atrium; $N$, noncoronary cusp; R, right coronary cusp; RV, right ventricle.

THV-related mitral stenosis, or regurgitation [Grube 2007; Piazza 2009; Ussia 2010; Balghith 2012; Harries 2015; Auer 2017; Franco 2012]. Suboptimal deployment is regarded as mild malposition of the THV, in which the patient remains hemodynamically stable but the THV is not in the right annular plane. Ibebuogu et al [2015] reviewed a group of 71 patients with THV embolization and revealed that in $90 \%$ of

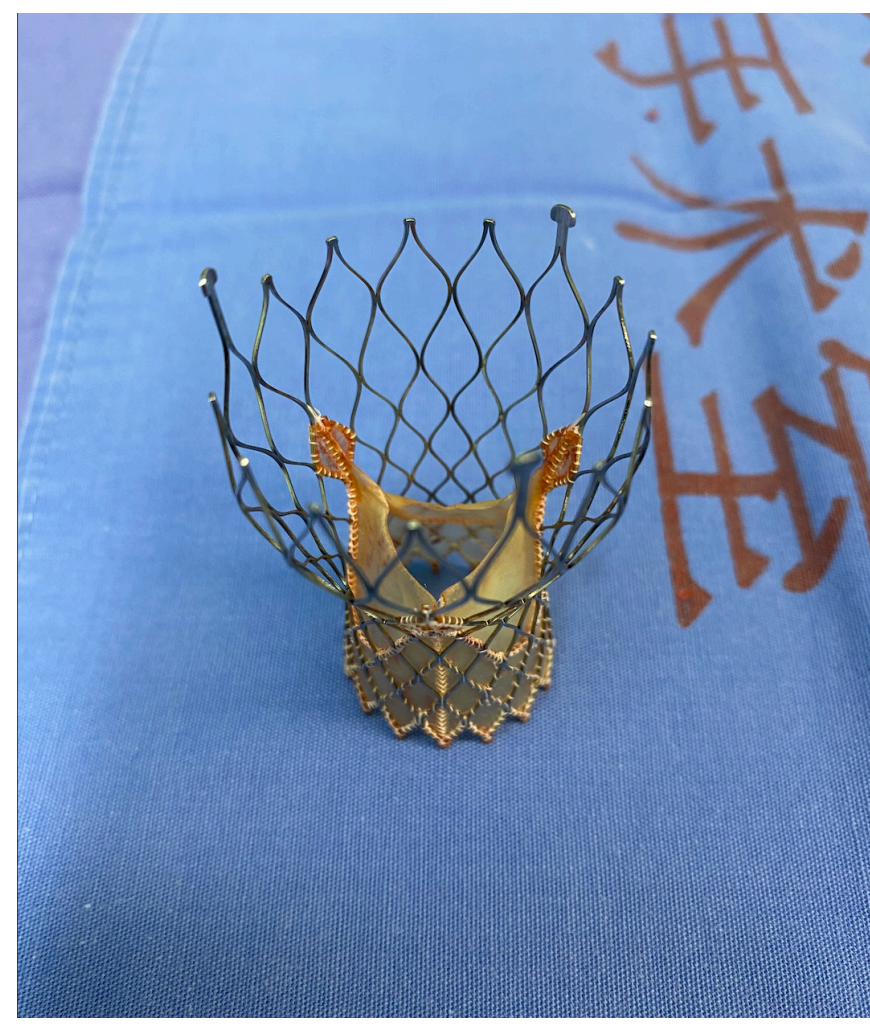

Figure 4. The 26\# Venus A-Valve was removed after infiltration with ice water.

cases, embolization occurred immediately after implantation. The most common sites of embolization were the ascending aorta $(38 \%)$ and left ventricle $(31 \%)$.

Transcatheter valve-in-valve technique has become an established technique to treat acute THV failure [Makkar 2013]. The bailout of conversion to open-heart surgery has been considered the last backup, although it is associated with high mortality during hospitalization. Transcatheter management of THV misplacement with a low deployment has been reported by Ussia et al [2010]. This technique uses a gooseneck catheter to snare hooks of the prosthesis and carefully pull the valve. But a time-consuming technique seems riskier and inoperable in a cardiogenic shock patient. Therefore, a judicious procedure to prevent a low deployment is crucial. In terms of operator technique: (1) an extremely slow release of the Venus A-Valve is mandatory even in an emergent setting, given that the device has a lack of 1:1 delivery and superradial force increases the possibility of diving into the left ventricle outflow tract; and (2) the "cusp-overlap technique" with en face view of the noncoronary cusp ensures a higher deployment, which may decrease the possibility of diving [Tang 2018]. We suggest that the next-generation Venus A-Valve device have the following advantages: (1) ability of recapture and reposition; (2) a 1:1 delivery system; and (3) refinement of its superradial force and rigid frame.

Although several bailouts after malpositioning of THV have been reported, a widespread and practical percutaneous technique to manage the implant failure of THV is required 
Table 1. Classification of THV Malposition*

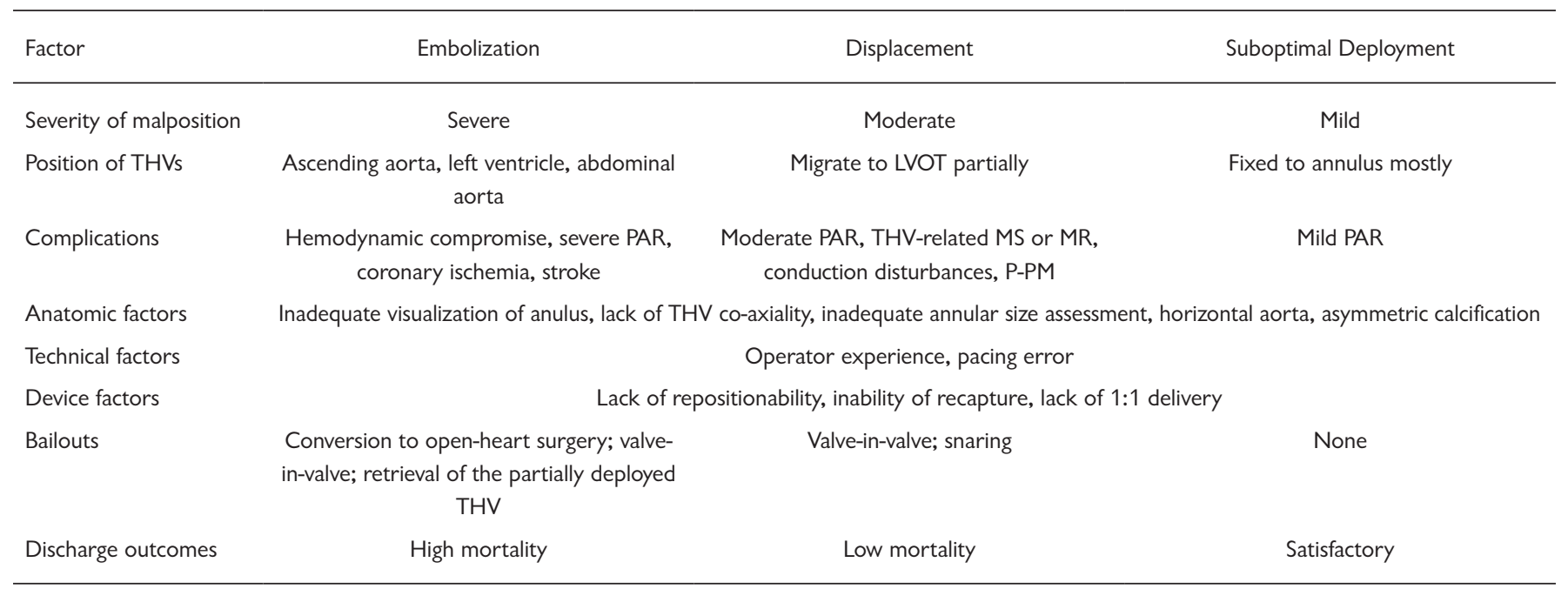

*LVOT indicates left ventricle outflow tract; MR, mitral regurgitation; MS, mitral stenosis; PAR, paravalvular aortic regurgitation; P-PM, prosthesis-patient mismatch; THV, transcatheter heart valve.

with the following trackability: (1) the technique is practical, with a short learning curve, because the incidence of implant failure is low; (2) the technique has high reproducibility; and (3) the technique is timesaving.

\section{CONCLUSION}

TAVR may be an option for patients at high surgical risk with cardiogenic shock and severe aortic stenosis. Malpositioning of the Venus A-Valve bioprosthesis predicts paravalvular aortic regurgitation and is associated with P-PM. Malpositioning of the THV is an essential determinant of morbidity and mortality after TAVR. A widespread and practical percutaneous technique to manage the implant failure of $\mathrm{THV}$ is required to avoid surgical bailout.

\section{ACKNOWLEDGMENTS}

This study was supported in part by the Beijing Municipal Administration of Hospitals Clinical Medicine development of special funding support (No. ZYLX201503) and Beijing Municipal Natural Science Foundation (No. 7202038).

\section{REFERENCES}

Auer J, Grund M, Puschmann R, Berent R. Acute severe mitral stenosis immediately after transcatheter aortic valve implantation. J Invasive Cardiol 2017;29:E154.

Balghith M, Omran A, Saileek A, Alghamdi A, Najm H. Transcatheter aortic valve implantation (core valve) prosthesis complicated by mitral stenosis. J Saudi Heart Assoc 2012;24:149-150.
Baumgartner H, Falk V, Bax JJ, De Bonis M, Hamm C, Holm PJ, et al. $2017 \mathrm{ESC} / \mathrm{EACTS}$ Guidelines for the management of valvular heart disease. Eur Heart J 2017;38:2739-2791.

Fraccaro C, Campante Teles R, Tchetche D, Saia F, Bedogni F, Montorfano $\mathrm{M}$, et al. Transcatheter aortic valve implantation (TAVI) in cardiogenic shock: TAVI-shock registry results. Catheter Cardiovasc Interv 2020;96:1128-1135.

Franco E, de Agustin JA, Hernandez-Antolin R, Garcia E, Silva J, Maroto $\mathrm{L}$, et al. Acute mitral stenosis after transcatheter aortic valve implantation. J Am Coll Cardiol 2012;60:e35.

Geisbusch S, Bleiziffer S, Mazzitelli D, Ruge H, Bauernschmitt R, Lange R. Incidence and management of CoreValve dislocation during transcatheter aortic valve implantation. Circ Cardiovasc Interv 2010;3:531-536.

Grube E, Schuler G, Buellesfeld L, Gerckens U, Linke A, Wenaweser $\mathrm{P}$, et al. Percutaneous aortic valve replacement for severe aortic stenosis in high-risk patients using the second- and current third-generation self-expanding CoreValve prosthesis: Device success and 30-day clinical outcome. J Am Coll Cardiol 2007;50:69-76.

Harries I, Chandrasekaran B, Barnes E, Ramcharitar S. Iatrogenic mitral stenosis following transcatheter aortic valve replacement (TAVR). Indian Heart J 2015;67:60-61.

Ibebuogu UN, Giri S, Bolorunduro O, Tartara P, Kar S, Holmes D, et al. Review of reported causes of device embolization following trans-catheter aortic valve implantation. Am J Cardiol 2015;115:1767-1772.

Jilaihawi H, Chin D, Spyt T, Jeilan M, Vasa-Nicotera M, Bence J, et al. Prosthesis-patient mismatch after transcatheter aortic valve implantation with the Medtronic-Corevalve bioprosthesis. Eur Heart J 2010;31:857-864.

Makkar RR, Jilaihawi H, Chakravarty T, Fontana GP, Kapadia S, Babaliaros V, et al. Determinants and outcomes of acute transcatheter valve-in-valve therapy or embolization: A study of multiple valve implants in the U.S. PARTNER trial (Placement of AoRTic TraNscathetER Valve Trial Edwards SAPIEN Transcatheter Heart Valve). J Am Coll Cardiol 


\section{$2013 ; 62: 418-430$.}

Piazza N, Schultz C, de Jaegere PP, Serruys PW. Implantation of two self-expanding aortic bioprosthetic valves during the same procedureInsights into valve-in-valve implantation ("Russian doll concept"). Catheter Cardiovasc Interv 2009;73:530-539.

Pibarot P, Hahn RT, Weissman NJ, Monaghan MJ. Assessment of paravalvular regurgitation following TAVR: A proposal of unifying grading scheme. JACC Cardiovasc Imaging 2015;8:340-360.

Sarkar K, Ussia G, Tamburino C. Core Valve embolization: Technical challenges and management. Catheter Cardiovasc Interv 2012;79:777-782

Tang GHL, Zaid S, Michev I, Ahmad H, Kaple R, Undemir C, et al. "Cusp-overlap" view simplifies fluoroscopy-guided implantation of self-expanding valve in transcatheter aortic valve replacement. JACC Cardiovasc Interv 2018;11:1663-1665.

Tay EL, Gurvitch R, Wijeysinghe N, Nietlispach F, Leipsic J, Wood DA, et al. Outcome of patients after transcatheter aortic valve embolization. JACC Cardiovasc Interv 2011;4:228-234.

Ussia GP, Barbanti M, Imme S, Scarabelli M, Mule M, Cammalleri V, et al. Management of implant failure during transcatheter aortic valve implantation. Catheter Cardiovasc Interv 2010;76:440-449.

Ussia GP, Barbanti M, Ramondo A, Petronio AS, Ettori F, Santoro G, et al. The valve-in-valve technique for treatment of aortic bioprosthesis malposition an analysis of incidence and 1-year clinical outcomes from the italian CoreValve registry. J Am Coll Cardiol 2011;57:1062-1068. 